\title{
Circadian rhythms and sleep-the metabolic connection
}

\author{
Urs Albrecht
}

Received: 26 April 2011 /Revised: 7 June 2011 / Accepted: 8 June 2011 / Published online: 28 June 2011

(C) Springer-Verlag 2011

\begin{abstract}
The circadian system coordinates mammalian physiology and behavior with the environmental light-dark cycle. It allocates sleep to the inactivity phase using various mechanisms involving neurotransmitters, nuclear receptors, and protein kinases. These pathways are related to metabolism, indicating that the circadian system and sleep are connected via metabolic parameters. This suggests that organs other than the brain may "sleep." A hypothetic view on this aspect is presented providing a different perspective on sleep regulation.
\end{abstract}

Keywords Nuclear receptors $\cdot$ Neurotransmitters $\cdot$ Protein kinases $\cdot$ Metabolism $\cdot$ AMPK $\cdot$ Cell death $\cdot$ Apoptosis .

Adenosine $\cdot$ ATP release $\cdot$ Catecholamines $\cdot$ cGMP .

Circadian rhythm $\cdot$ Gene expression - Liver .

Neuroendocrinology $\cdot$ Protein kinase $\cdot$ Sleep apnea

\section{Introduction}

Life on earth has been exposed to a periodic occurrence of light and darkness during its evolution. This steady change of light and darkness has been incorporated in the form of a circadian rhythm in order to schedule biochemical and physiological processes to their optimal phase during the $24 \mathrm{~h}$ of a day (for the molecular makeup, see [66], this issue). In mammals, a day can roughly be divided into an

This article is published as part of the Special Issue on Sleep.

U. Albrecht $(\bowtie)$

Department of Biology, Unit of Biochemistry,

University of Fribourg,

Chemin du Musée 5,

1700 Fribourg, Switzerland

e-mail: urs.albrecht@unifr.ch activity phase, during which physical activity is predominant, and a rest phase, during which repair mechanisms become active and brain function alters into a state of sleep. Hence, sleep is a periodically occurring state of rest and lack of interaction with the environment. However, sleep appears to be more than simply switching off wakefulness; it appears to be a highly regulated process involving mainly two mechanisms: (1) a homeostatic process regulating the increase for readiness to fall asleep during wakefulness and the decrease of sleep intensity during sleep and (2) a circadian process that schedules sleep and wakefulness to the appropriate times within 1 day and is mostly independent of previous sleep/wake episodes [9].

These two mechanisms describe sleep at the systemic level. However, in the last decade, the circadian system could be analyzed in a very systematic manner due to the identification of genes making up transcriptional-translational autoregulatory feedback loops building the base for a clock mechanism at the cellular level. This has paved the way to analyze mice with mutations in specific clock genes and their effect on sleep parameters [58, 66]. Circadian parameters were most of the time affected; however, homeostatic parameters, such as delta power, have been affected only in a few cases $[21,79]$. This indicates that at the molecular level, additional mechanisms determine the homeostatic contribution to sleep.

Deciphering the molecular base of sleep has been very difficult. This may have several reasons. First, it is very likely that the homeostatic and circadian processes are interlaced to some degree, which makes it difficult to clearly separate the two processes and the mechanisms involved. Second, the definition of sleep is focused on the brain and its activity, since lack of sleep manifests first in lack of interaction with the environment due to changes in brain activity. However, due to the reasons mentioned 
above, the influence of the circadian component on sleep is becoming better understood. The influence of circadian rhythms on neurotransmitter expression and their action on sleep via their receptors is an emerging topic [71]. Regulation of neurotransmitter expression directly via clock components binding to E-boxes in promoters of the corresponding genes [35] as well as indirect regulation via nuclear receptors modulated by clock components such as PER2 [63] may shed new light on the interaction between circadian rhythms and sleep. Furthermore, binding of neurotransmitters to their receptors uncovers a variety of signaling pathways that are potentially involved in the activation of genes important for sleep regulation such as, for example, metabolic regulators (adenosine) and regulators of neuronal plasticity [2].

\section{Neurotransmitters, sleep, and circadian rhythms}

Neurotransmitters serve to modulate brain activity in either a positive or negative manner. There are two main groups of neurotransmitters, those that facilitate sleep and those that facilitate arousal.

Excitatory neurotransmitters such as noradrenaline, serotonin, histamine, acetylcholine, and orexin are released during wake from their respective neurons in the locus ceruleus, dorsal raphe/thalamus, tuberomammillary nucleus/ posterior hypothalamus, basal forebrain/lateral tegmentum, and lateral hypothalamus, respectively. At the same time, the release of inhibitory neurotransmitters such as gammaaminobutyric acid (GABA) and galanin from the ventrolateral preoptic nucleus (VLPO) is suppressed to favor the state of wakefulness.

Orexin-A and orexin-B (hypocretin-1 and hypocretin-2) are excitatory neuropeptide hormones that stimulate wakefulness and energy expenditure and are thought to stimulate food intake [17, 60]. Interestingly, orexin immunoreactivity shows diurnal variation in the rat central nervous system [72] and in cerebrospinal fluid of humans [26, 61] suggesting that this peptide may be regulated by the circadian clock mechanism or mechanisms for clock adaptation. This is supported by the findings that dark pulses activate orexin neurons [47]. Hence, there may be a reciprocal relationship between circadian cues and arousalpromoting signals arising from orexin neurons. However, it remains to be seen whether the orexin promoter can be modulated by clock components providing a direct link between circadian and arousal-promoting signals.

Sleep-promoting signals such as melatonin, glycine, GABA, and adenosine are released from the pineal gland, the spinal cord, and the VLPO or accumulate in the basal forebrain in the case of adenosine. This happens in an ordered fashion. First, all aminergic and cholinergic neuro- transmitters and orexin (see above) are inhibited through VLPO-mediated GABA and galanin release. This decreases arousal. Then, acetylcholine originating from neurons in the brainstem, midbrain, and basal forebrain is released as well as orexin. GABA and galanin that are released from the brainstem and VLPO act to inhibit the aminergic brainstem neurons (for detailed mechanism of sleep state switching, see [62]).

The switch from wake to sleep appears to correlate with the accumulation of the ATP breakdown product adenosine during wakefulness [6]. This occurs especially in the basal forebrain and correlates with sleep pressure. Adenosine inhibits GABAergic basal forebrain neurons, which act to inhibit the sleep-promoting neurons of the VLPO. Disinhibition of the VLPO promotes release of GABA and galanin, which in turn inhibit the arousal-promoting system in the brainstem, midbrain, and basal forebrain, thereby initiating sleep. Hence, it appears that sleep may have a metabolic function to avoid buildup of metabolic waste that may be harmful for the cell (see below). Of note here is that metabolic parameters also intersect with circadian rhythms [27].

In the pineal gland, melatonin production rises after the activity period via activation of pineal beta-adrenergic receptors activated by noradrenaline. This results in elevation of adenosine monophosphate (5'-AMP) and increases the synthesis of the rate-limiting enzyme of melatonin synthesis, the arylalkylamine- $N$-acetyltransferase (Aanat) (reviewed in [32]). There is evidence that the synthesis of Aanat mRNA is regulated by the circadian clock by translational mechanisms [38]. Direct interaction of clock components with the E-box present in the promoter of the Aanat gene appears to modulate its expression also transcriptionally in a time-dependent fashion [29]. This highlights additional interactions between circadian rhythms and sleep regulation. Taken together, it appears that several neurotransmitters involved in the regulation of sleep are directly regulated by clock components and hence represent intersections between circadian rhythms and sleep.

\section{Nuclear receptors, sleep, and circadian rhythms}

Nuclear receptors are proteins that bind organic compounds such as hormones and translocate upon ligand binding into the nucleus of a cell. There they directly bind to DNA and regulate expression of genes and therefore are classified as transcription factors. The heme binding nuclear receptor REV-ERB $\alpha$ (NR1D1) [82] is part of the circadian clock machinery [55] and may influence sleep patterns via alterations in the circadian component of sleep. However, animals lacking this nuclear receptor have not been tested for sleep parameters. 
Since nuclear receptors are transcription factors, there is the possibility that they may affect expression of important neurotransmitters affecting sleep. Recently, the nuclear receptor germ cell nuclear factor (aka NR6A1) was identified to regulate orexin transcription [73]. However, whether absence of NR6A1 in the brain affects sleep remains to be demonstrated. The levels of non-peptide neurotransmitters such as dopamine and serotonin may be modulated by nuclear receptors via transcriptional regulation of rate-limiting enzymes responsible for their synthesis and/or degradation. Nurr1 (NR4A2) directly transactivates the promoter of the tyrosine hydroxylase gene $(\mathrm{TH})$, which encodes for the rate-limiting enzyme in dopamine synthesis [37]. Interestingly, this nuclear receptor interacts with the clock protein PER2 [63], which modulates NR4A2 activity [59]. Hence, TH expression may be affected by the circadian clock. Furthermore, it appears that clock components regulate the promoter of the Maoa gene [28], which encodes for the rate-limiting enzyme for dopamine degradation. This may be one of the reasons why mice with mutations in clock genes display alterations in sleep parameters [20, 22, 39, 44]. The regulation of dopamine by nuclear receptors may also affect noradrenaline synthesis, since this molecule is synthesized from dopamine by the enzyme dopamine $\beta$-hydrolase. The synthesis of the other catecholamine that affects sleep, serotonin, is controlled by tryptophan hydroxylase- 2 in the brain [84]. This enzyme is regulated by the estrogen receptor beta (NR3A2) within serotonergic neurons of the dorsal raphe nuclei [19] indicating the involvement of nuclear receptors in regulation of production of this neurotransmitter. Interestingly, it appears that under certain conditions the estrogen receptor beta (NR3A2) may interact with PER2 [24], and therefore, its activity is possibly influenced by the clock mechanism.

Retinoids (including vitamin A) appear to modulate sleep regulation probably by affecting the homeostatic component of sleep (reviewed in [65]). Sleep deprivation (SD) leads to changes in gene expression in the brain. One gene that is significantly affected by SD is transthyretin [65], a critical transporter protein for retinol. Genetic linkage analysis in various mouse strains with varying slow wave sleep (SWS) revealed that retinoic acid receptor beta (RARB aka NR1B2) may be linked to changes in SWS. Analysis of mice mutant in the Rarbl gene revealed that this is indeed the case [46]. Hence, it appears that retinoic acid-mediated transcriptional events affect cortical synchrony during sleep. Consistent with this finding is the observation that a vitamin A-deficient diet causes attenuation of delta oscillations, a correlate of sleep depth and sleep need in the electroencephalogram (EEG) of SWS [65]. In conclusion, it appears that RARB and its ligand are modulating the homeostatic component of sleep. Of note is that $\mathrm{RARB}$ receptors have been hypothesized to play an important role in the mesolimbic dopaminergic pathway [40], which is involved in addiction processes and regulation of mood [50]. The other receptor that can bind retinoids, retinoic $\mathrm{X}$ receptor alpha (NR2B1), heterodimerizes with Nurr1 (NR4A2) and NGFI-B (Nur77 aka NR4A1) [53]. Since Nurr1 regulates $\mathrm{TH}$, retinoids may affect the synthesis of dopamine [42]. Hence, retinoids may affect sleep via regulation of dopamine production. How the Nurr1 interacting clock gene PER2 is involved in this process remains to be determined.

\section{Protein kinases, sleep, and circadian rhythms}

Protein kinases play an important role in the circadian clock mechanism [76]. A mutation in casein kinase I $\delta$ (CKI $\delta$ ) leads to familial advanced sleep phase syndrome [80], by affecting phosphorylation of a specific serine residue in the clock protein PER2 and hence disturbing the circadian component of sleep.

The light-mediated resetting mechanism of the circadian clock involves a number of kinases, including CKI. There is genetic evidence that cGMP-dependent protein kinase II (PKGII) modulates the size of resetting in response to light [51]. In contrast, cGMP-dependent protein kinase I (PKGI) regulates the timing and quality of sleep and wakefulness but not resetting of the circadian clock [43]. Interestingly, the Caenorhabditis elegans homolog of PKGI appears to influence lethargus, a sleep-like state in these animals [57]. Since cGMP-dependent protein kinases can mediate nitric oxide (NO) signaling in the nervous system, NO may influence parameters of sleep. In accordance with this hypothesis is the observation that NO affects recovery sleep [36].

The MAP-kinase signaling pathway is involved in the resetting of the circadian clock machinery in response to light (reviewed in [31]) and also appears to affect sleep. For example, selective increase of rapid eye movement (REM) sleep in HIV-infected subjects can be prevented by an inhibitor of the ERK activating enzyme MEK [18]. Hence, the MAP-kinase pathway appears to be involved in REMS regulation. Additionally, there is genetic evidence that protein kinase A (PKA) signaling plays a role in the maintenance of sleep [30]. This is also supported by the finding of a single nucleotide polymorphism in the phosphodiesterase 4D (PDE4D) gene that is associated with sleepiness in humans [25]. PDE4D reduces cAMP levels and thereby reduces PKA activity. REM sleep deprivation leads to activation of PKA in the pedunculopontine tegmental nucleus [16], a critical area of the brainstem for the regulation of REM sleep. Hence, activation of PKA 
seems to be a critical step for the homeostatic regulation of REM sleep.

Glycogen synthase kinase $3 \beta$ (GSK3 $\beta$ ) phosphorylates and stabilizes the clock component and nuclear receptor Rev-erb $\alpha$ [81]. This may be linked to the observation that transgenic mice overexpressing GSK3 $\beta$ exhibit severe fragmentation of the sleep-wake cycle without showing deviancy in total duration of vigilance states [1]. In humans, a single nucleotide polymorphism in the promoter of GSK3 $\beta$ is associated with response to total sleep deprivation in bipolar depression [5]. Taken together, it appears that GSK3 $\beta$ may modulate sleep-wake organization and recovery sleep. However, a mechanistic chain of events is still lacking.

Calcium/calmodulin-dependent protein kinase IV (CaMKIV), which is involved in synaptic plasticity [78], synaptic homeostasis [33], and learning and memory [23], is upregulated following sleep [13]. Overexpression of CaMKIV in mice selectively enhances $4-7.5 \mathrm{~Hz}$ oscillation power during trace fear learning and $1-4 \mathrm{~Hz}$ delta oscillations during subsequent sleep [67]. This emphasizes a role for CaMKIV in the control of learning and sleep-related EEG oscillations.

The mRNA of another calcium/calmodulin-dependent protein kinase, CaMKK2, is increased after $6 \mathrm{~h}$ of SD. This kinase is an activator of adenosine monophosphate (AMP)activated protein kinase (AMPK), a sensor and central mediator of metabolic signals. Consequently, AMPK is phosphorylated, and p-AMPK is increased after SD [12] and hence leads to higher AMPK activity. Pharmacological treatment of mice with AMPK inhibitor and activator modulated EEG delta power indicating that AMPK is involved in the regulation of sleep depth and sleep homeostasis [12]. Recent investigations also point to an involvement of AMPK in the regulation of the circadian oscillator. The clock protein CRY1 is phosphorylated and destabilized by AMPK [41] affecting the oscillator mechanism of the clock. Also, CKI $\varepsilon$ is activated by AMPK, which leads to PER2 degradation and phase advance in the circadian expression of clock genes [75]. Deletion of AMPK leads to changes of circadian rhythms in a tissue- and isoform-specific manner [74]. Since AMPK is a nutrient sensor, it appears that metabolic status may affect the circadian component of sleep via CRY1 and PER2 phosphorylation linking metabolism and sleep.

Adenosine plays an important role in sleep regulation $[6,56]$. Extracellular ATP is rapidly degraded by ectonucleotidases [85], some of which are expressed in a timedependent fashion [83]. The resulting adenosine accumulates in the extracellular space and is taken up by astrocytes via equilibrative nucleoside transporters [4]. Inside the cell, adenosine is phosphorylated by adenosine kinase (ADK) to 5 '-AMP. Hence, ADK drives the influx of adenosine into the astrocytes and regulates the abundance of extracellular adenosine, and therefore, ADK is the primary enzyme regulating adenosine metabolism in rodents [8, 48]. In accordance with the notion of adenosine being an important sleep regulator, overexpression of the cytoplasmic isoform of ADK altered sleep physiology in mice [52]. Interestingly, however, reduced expression had no major effect on sleep [52].

Taken together, the above illustrates the importance of protein kinases in sleep and circadian clock regulation. Most likely, more protein kinases and phosphatases, the counterplayers of kinases, are involved in the regulation of sleep.

\section{Metabolism, an intersection between the circadian and the homeostatic process of sleep?}

Most of the neurotransmitters, nuclear receptors, and protein kinases that regulate sleep are involved in the regulation of metabolism as well. Therefore, metabolism may be the focal point between the regulation of the circadian and homeostatic process of sleep. In 1995, Benington and Heller [6] proposed that during wake, metabolism is increased in the brain, leading to a rise in adenosine levels. Adenosine is an inhibitory neuromodulator in the central nervous system, inhibiting neuronal activity of excitatory (e.g., cholinergic and glutamatergic) as well as inhibitory (e.g., GABAergic) neurons [70]. The rate of adenosine formation increases when the supply-to-demand ratio for oxygen is decreasing. In other words, if more oxygen is needed than can be supplied as observed in hypoxia, neuronal activity is shut down (for review, see [54]). This may be important to protect neurons from selfdestruction and to minimize cell damage [15]. Interestingly, adenosine levels increase during SD in the basal forebrain of rats, but not in the thalamus, dorsal raphe nucleus, pedunculopontine tegmental nucleus, and preoptic area (for review, see [54]). This regionally specific rise in adenosine in response to SD supports the hypothesis that adenosine promotes sleep via modulation of neuronal activity in the basal forebrain.

However, it is not clear how extracellular ATP levels are regulated. The ATP produced in mitochondria leads to a steady-state cytosolic concentration of ATP of about $10 \mathrm{mM}$. Extracellular ATP is approximately $10 \mathrm{nM}$ under basal conditions. Hence, the ATP gradient for ATP secretion or efflux is about $10^{6}$-fold. Interestingly, this gradient is 100 times greater, yet opposite, to the gradient for calcium entry into cells. Therefore, if a pathway is activated or a channel opened for ATP release, ATP would exit the cell down a very favorable gradient. It should be emphasized, however, that only $1 \%$ or less of the intracellular ATP pool is 
necessary to activate its own or its derivative's receptors. Thus, extracellular ATP signaling can occur without compromising cellular metabolism or essential enzymatic reactions (reviewed in [64]).

After conversion of ATP to adenosine and uptake of adenosine into the cell, ADK phosphorylates adenosine to 5'-AMP (see above). 5'-AMP signals to the cell that energy should be mobilized from the organism's storage sites. This molecule allosterically regulates the following key metabolic, (catabolic and anabolic) enzymes. On the catabolic side, AMPK is activated by $5^{\prime}$-AMP, which leads to increase in nicotinamide phosphoribosyl transferase, and intracellular NAD+ levels rise. This enhances SIRT1 activity leading to deacetylation of its targets such as PGC- $1 \alpha[10,11]$ to increase fatty acid oxidation. The ratelimiting enzyme of glycolysis, phosphofructokinase, is positively regulated by $5^{\prime}$-AMP dictating the catabolism of glucose. Glycogen catabolism is also positively regulated by $5^{\prime}$-AMP via activation of the rate-limiting enzyme glycogen phosphorylase, which liberates glucose from glycogen. Anabolic reactions such as gluconeogenesis, however, are inhibited by 5 '-AMP by negative regulation of fructose-1,6-diphosphatase (reviewed in [45]). Taken together, 5'-AMP activates catabolic pathways and inhibits anabolic pathways. This is in line with the view that adenosine promotes sleep. During inactivity, energy will be supplied by the body's stores, and hence, catabolic pathways need to be activated. Interestingly, many of the enzymes highlighted here are involved in the regulation of the circadian system.

The liver is the central organ for metabolic regulation. Patients with liver cirrhosis display fragmented sleep, delayed sleep habits, take longer to fall asleep, and nap frequently during the day [7, 14]. The pathophysiology of these abnormalities is unknown, but patients with liver cirrhosis might be interesting to study from the point of view of a disturbed circadian system. Under the assumption that cirrhotic patients do not have a circadian rhythmically active liver, these patients model a clock system with disturbance of peripheral but not central clocks. Hence, the importance of peripheral circadian liver metabolic rhythms can be studied in terms of their relevance for sleep. In this context, the metabolism of melatonin, a sleep-promoting molecule, synthesized in the pineal gland has been studied. Melatonin is transformed to 6-sulphatoxymelatonin (aMT6s) in the liver $[3,34]$ and is excreted in the urine. Abnormalities in the rhythm of both plasma melatonin and urinary aMT6s have been observed in patients with cirrhosis, and this may contribute to sleep disturbances $[68,69]$. A significant association has been observed between aMT6s profiles and delayed sleep timing in patients with cirrhosis [49] indicating at least a disturbance of the circadian component of sleep in these patients.

\section{The hourglass and "sleeping" cells}

The circadian as well as the homeostatic component of sleep are related to metabolism. This is probably one of the reasons why the two processes cannot be clearly separated from each other. In contrast to the circadian component, the mechanistic workings of the homeostatic component are far from understood. The following hypothesis may aid in better understanding and investigating the homeostat in the future. The homeostat may be viewed as a counter of the filling state of a metabolic trash bin. During the active phase, metabolism is mainly running in one direction, and toxic products such as, for example, peroxides may accumulate. Under normal conditions, the circadian component will signal the appropriate time for the organism to inverse the biochemical pathways and regenerate its enzymes and detoxify the cells which have accumulated toxic products (e.g., peroxides). This will put the cell back to its initial metabolic state in a circadian fashion (Fig. 1). However, the circadian signal may be overruled by prolonged activity or sleep deprivation, which may be necessary under extreme circumstances. As a consequence, toxic metabolic products accumulate. In other words, the trash bin fills up over the normal levels limited by the circadian signal. This still can be tolerated, but a safety mechanism needs to be in place to define the maximal levels of toxic substances allowed in the cell to protect it from destruction. Such a metabolic meter will ultimately force the cell to go into the "regenerative" state, irrespective of other signals. The initial state of the cell will be reached via such an hourglass mechanism-like process (Fig. 1). This may happen in all cell types. However, neurons are

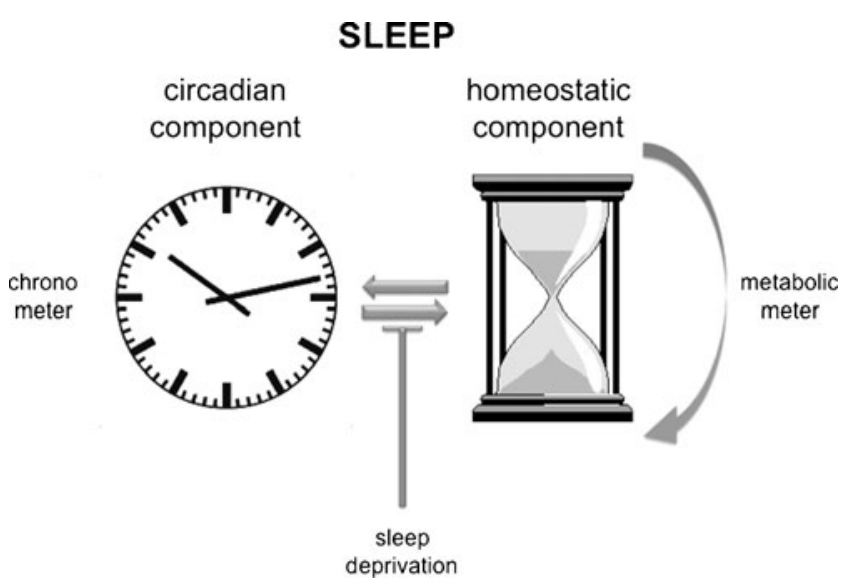

Fig. 1 A circadian and a homeostatic component regulate sleep in mammals. The circadian component corresponds to a chronometer (left) whereas the homeostatic component corresponds to a metabolic meter with an hourglass-like mechanism. The two components interact but can be uncoupled by sleep deprivation 
somewhat special in this respect, because they are more sensitive to toxic substances than other cell types. This may be the reason why this effect is seen first in the brain in the form of shutting down the awake state of brain activity.

Recently, "local" sleep in the brain of rats was observed [77]. After a long period of awake state, cortical neurons were observed to go briefly "offline" accompanied by slow wave sleep in the local EEG. The switch to go "offline" appeared to affect only some areas in the brain but not others at a given time, indicating the existence of "local sleep." The incidence of this process appeared to increase with the duration of the awake state, and animals showed an overall "awake" EEG. Hence, local populations of neurons may fall asleep without affecting the awake appearance of the animal, although impairing its motor performance slightly. This local regulation of sleep in individual neurons will allow the animal to have some neuronal circuits still running while others are idling. This would help the animal to perform task important for survival for a longer period than predicted by the circadian timer. These observations are in line with the view presented above to rest "tired" metabolically exhausted neurons and allow them to regenerate, avoiding accumulation of cytotoxic substances. It remains to be seen whether such neurons die, when not allowed to rest, which would be a prediction of the model postulated above.

The model presented above would also predict that basically all cells and organs have the potential to sleep. However, the central position of the brain allows it to regulate the function of other organs via neuronal and hormonal signaling. Therefore, the brain may be communicating "sleep" to organs before they are instructed by their own metabolic meter to go into a "regenerative" state. Hence, sleep may not be observed in organs under normal circumstances. Under stressful conditions, however, when cells in peripheral organs are "overused" and not allowed to regenerate (e.g., liver cirrhosis), cells will die as a consequence. These cells will then be replaced with newly differentiated cells originating form local progenitor cells. This process is less efficient in the brain and hence, metabolic control is more stringent in this tissue. Although the hypothesis described here has many appealing facets, it is certainly simplistic. Nevertheless, the view presented here may be useful to look at sleep from a different perspective.

Acknowledgments I would like to thank Dr. Jürgen Ripperger for critical reading of the manuscript. U.A. is supported by the Swiss National Science foundation (SNF), the State of Fribourg, and the Japanese-Swiss Science and Technology Programme.

\section{References}

1. Ahnaou A, Drinkenburg WH (2011) Disruption of glycogen synthase kinase-3-beta activity leads to abnormalities in physio- logical measures in mice. Behav Brain Res 221(1):246-252. doi:10.1016/j.bbr.2011.03.004

2. Appelbaum L, Wang G, Yokogawa T, Skariah GM, Smith SJ, Mourrain P, Mignot E (2010) Circadian and homeostatic regulation of structural synaptic plasticity in hypocretin neurons. Neuron 68(1):87-98. doi:10.1016/j.neuron.2010.09.006

3. Arendt J, Bojkowski C, Franey C, Wright J, Marks V (1985) Immunoassay of 6-hydroxymelatonin sulfate in human plasma and urine: abolition of the urinary 24-hour rhythm with atenolol. J Clin Endocrinol Metab 60(6):1166-1173

4. Baldwin SA, Beal PR, Yao SY, King AE, Cass CE, Young JD (2004) The equilibrative nucleoside transporter family, SLC29. Pflugers Arch 447(5):735-743. doi:10.1007/s00424-003-1103-2

5. Benedetti F, Bernasconi A, Lorenzi C, Pontiggia A, Serretti A, Colombo C, Smeraldi E (2004) A single nucleotide polymorphism in glycogen synthase kinase 3-beta promoter gene influences onset of illness in patients affected by bipolar disorder. Neurosci Lett 355(1-2):37-40

6. Benington JH, Heller HC (1995) Restoration of brain energy metabolism as the function of sleep. Prog Neurobiol 45(4):347-360

7. Bianchi G, Marchesini G, Nicolino F, Graziani R, Sgarbi D, Loguercio C, Abbiati R, Zoli M (2005) Psychological status and depression in patients with liver cirrhosis. Dig Liver Dis 37 (8):593-600. doi:10.1016/j.dld.2005.01.020

8. Boison D (2006) Adenosine kinase, epilepsy and stroke: mechanisms and therapies. Trends Pharmacol Sci 27(12):652658. doi:10.1016/j.tips.2006.10.008

9. Borbely AA (1998) Processes underlying sleep regulation. Horm Res 49(3-4):114-117

10. Canto C, Gerhart-Hines Z, Feige JN, Lagouge M, Noriega L, Milne JC, Elliott PJ, Puigserver P, Auwerx J (2009) AMPK regulates energy expenditure by modulating NAD + metabolism and SIRT1 activity. Nature 458(7241):1056-1060. doi:10.1038/nature07813

11. Canto C, Jiang LQ, Deshmukh AS, Mataki C, Coste A, Lagouge M, Zierath JR, Auwerx J (2010) Interdependence of AMPK and SIRT1 for metabolic adaptation to fasting and exercise in skeletal muscle. Cell Metab 11(3):213-219. doi:10.1016/j.cmet.2010.02.006

12. Chikahisa S, Fujiki N, Kitaoka K, Shimizu N, Sei H (2009) Central AMPK contributes to sleep homeostasis in mice. Neuropharmacology 57(4):369-374. doi:10.1016/j.neuropharm.2009.07.015

13. Cirelli C, Gutierrez CM, Tononi G (2004) Extensive and divergent effects of sleep and wakefulness on brain gene expression. Neuron 41 (1):35-43

14. Cordoba J, Cabrera J, Lataif L, Penev P, Zee P, Blei AT (1998) High prevalence of sleep disturbance in cirrhosis. Hepatology 27 (2):339-345. doi:10.1002/hep.510270204

15. Cunha RA (2005) Neuroprotection by adenosine in the brain: from $\mathrm{A}(1)$ receptor activation to $\mathrm{A}(2 \mathrm{~A})$ receptor blockade. Purinergic Signal 1(2):111-134. doi:10.1007/s11302-005-0649-1

16. Datta S, Desarnaud F (2010) Protein kinase A in the pedunculopontine tegmental nucleus of rat contributes to regulation of rapid eye movement sleep. J Neurosci 30(37):12263-12273. doi:10.1523/JNEUROSCI.1563-10.2010

17. de Lecea L, Kilduff TS, Peyron C, Gao X, Foye PE, Danielson PE, Fukuhara C, Battenberg EL, Gautvik VT, Bartlett FS 2nd, Frankel WN, van den Pol AN, Bloom FE, Gautvik KM, Sutcliffe JG (1998) The hypocretins: hypothalamus-specific peptides with neuroexcitatory activity. Proc Natl Acad Sci USA 95(1):322-327

18. Diaz-Ruiz O, Navarro L, Mendez-Diaz M, Galicia O, Elder JH, Sanna PP, Drucker-Colin R, Prospero-Garcia O (2001) Inhibition of the ERK pathway prevents HIVgp120-induced REM sleep increase. Brain Res 913(1):78-81

19. Donner N, Handa RJ (2009) Estrogen receptor beta regulates the expression of tryptophan-hydroxylase 2 mRNA within serotonergic neurons of the rat dorsal raphe nuclei. Neuroscience 163 (2):705-718. doi:10.1016/j.neuroscience.2009.06.046 
20. Dudley CA, Erbel-Sieler C, Estill SJ, Reick M, Franken P, Pitts S, McKnight SL (2003) Altered patterns of sleep and behavioral adaptability in NPAS2-deficient mice. Science 301(5631):379383. doi:10.1126/science. 1082795

21. Franken P, Dijk DJ (2009) Circadian clock genes and sleep homeostasis. Eur J Neurosci 29(9):1820-1829. doi:10.1111/ j.1460-9568.2009.06723.x

22. Franken P, Dudley CA, Estill SJ, Barakat M, Thomason R, O'Hara BF, McKnight SL (2006) NPAS2 as a transcriptional regulator of non-rapid eye movement sleep: genotype and sex interactions. Proc Natl Acad Sci USA 103(18):7118-7123. doi:10.1073/ pnas. 0602006103

23. Fukushima H, Maeda R, Suzuki R, Suzuki A, Nomoto M, Toyoda H, Wu LJ, Xu H, Zhao MG, Ueda K, Kitamoto A, Mamiya N, Yoshida T, Homma S, Masushige S, Zhuo M, Kida S (2008) Upregulation of calcium/calmodulin-dependent protein kinase IV improves memory formation and rescues memory loss with aging. J Neurosci 28 (40):9910-9919. doi:10.1523/JNEUROSCI.2625-08.2008

24. Gery S, Virk RK, Chumakov K, Yu A, Koeffler HP (2007) The clock gene Per2 links the circadian system to the estrogen receptor. Oncogene 26(57):7916-7920. doi:10.1038/sj.onc.1210585

25. Gottlieb DJ, O'Connor GT, Wilk JB (2007) Genome-wide association of sleep and circadian phenotypes. BMC Med Genet 8(Suppl 1):S9. doi:10.1186/1471-2350-8-S1-S9

26. Grady SP, Nishino S, Czeisler CA, Hepner D, Scammell TE (2006) Diurnal variation in CSF orexin-A in healthy male subjects. Sleep 29(3):295-297

27. Green CB, Takahashi JS, Bass J (2008) The meter of metabolism. Cell 134(5):728-742. doi:10.1016/j.cell.2008.08.022

28. Hampp G, Ripperger JA, Houben T, Schmutz I, Blex C, PerreauLenz S, Brunk I, Spanagel R, Ahnert-Hilger G, Meijer JH, Albrecht U (2008) Regulation of monoamine oxidase A by circadian-clock components implies clock influence on mood. Curr Biol 18(9):678-683. doi:10.1016/j.cub.2008.04.012

29. Haque R, Ali FG, Biscoglia R, Abey J, Weller J, Klein D, Iuvone PM (2010) CLOCK and NPAS2 have overlapping roles in the circadian oscillation of arylalkylamine $\mathrm{N}$-acetyltransferase mRNA in chicken cone photoreceptors. J Neurochem 113(5):1296-1306. doi:10.1111/j.1471-4159.2010.06698.x

30. Hellman K, Hernandez P, Park A, Abel T (2010) Genetic evidence for a role for protein kinase $\mathrm{A}$ in the maintenance of sleep and thalamocortical oscillations. Sleep 33(1):19-28

31. Hirota T, Fukada Y (2004) Resetting mechanism of central and peripheral circadian clocks in mammals. Zoolog Sci 21(4):359-368

32. Ho AK, Chik CL (2010) Modulation of Aanat gene transcription in the rat pineal gland. J Neurochem 112(2):321-331. doi:10.1111/ j.1471-4159.2009.06457.x

33. Ibata K, Sun Q, Turrigiano GG (2008) Rapid synaptic scaling induced by changes in postsynaptic firing. Neuron 57(6):819-826. doi:10.1016/j.neuron.2008.02.031

34. Jepson JB, Zaltzman P, Udenfriend S (1962) Microsomal hydroxylation of tryptamine, indoleacetic acid and related compounds, to 6-hydroxy derivatives. Biochim Biophys Acta 62:91-102

35. Jin X, Shearman LP, Weaver DR, Zylka MJ, de Vries GJ, Reppert SM (1999) A molecular mechanism regulating rhythmic output from the suprachiasmatic circadian clock. Cell 96(1):57-68

36. Kalinchuk AV, Lu Y, Stenberg D, Rosenberg PA, Porkka-Heiskanen $\mathrm{T}$ (2006) Nitric oxide production in the basal forebrain is required for recovery sleep. J Neurochem 99(2):483-498. doi:10.1111/ j.1471-4159.2006.04077.x

37. Kim KS, Kim CH, Hwang DY, Seo H, Chung S, Hong SJ, Lim JK, Anderson T, Isacson O (2003) Orphan nuclear receptor Nurrl directly transactivates the promoter activity of the tyrosine hydroxylase gene in a cell-specific manner. J Neurochem 85(3):622-634

38. Kim TD, Woo KC, Cho S, Ha DC, Jang SK, Kim KT (2007) Rhythmic control of AANAT translation by hnRNP Q in circadian melatonin production. Genes Dev 21(7):797-810. doi:10.1101/ gad. 1519507

39. Kopp C, Albrecht U, Zheng B, Tobler I (2002) Homeostatic sleep regulation is preserved in mPer1 and mPer2 mutant mice. Eur $\mathrm{J}$ Neurosci 16(6):1099-1106

40. Krezel W, Ghyselinck N, Samad TA, Dupe V, Kastner P, Borrelli E, Chambon $\mathrm{P}$ (1998) Impaired locomotion and dopamine signaling in retinoid receptor mutant mice. Science 279(5352):863-867

41. Lamia KA, Sachdeva UM, DiTacchio L, Williams EC, Alvarez JG, Egan DF, Vasquez DS, Juguilon H, Panda S, Shaw RJ, Thompson CB, Evans RM (2009) AMPK regulates the circadian clock by cryptochrome phosphorylation and degradation. Science 326(5951):437-440. doi:10.1126/science. 1172156

42. Lammi J, Perlmann T, Aarnisalo P (2008) Corepressor interaction differentiates the permissive and non-permissive retinoid $\mathrm{X}$ receptor heterodimers. Arch Biochem Biophys 472(2):105-114. doi:10.1016/j.abb.2008.02.003

43. Langmesser S, Franken P, Feil S, Emmenegger Y, Albrecht U, Feil R (2009) cGMP-dependent protein kinase type I is implicated in the regulation of the timing and quality of sleep and wakefulness. PLoS One 4(1):e4238. doi:10.1371/journal.pone.0004238

44. Laposky A, Easton A, Dugovic C, Walisser J, Bradfield C, Turek F (2005) Deletion of the mammalian circadian clock gene BMAL1/Mop3 alters baseline sleep architecture and the response to sleep deprivation. Sleep 28(4):395-409

45. Lehninger AL (1977) Biochemistry, 2nd edn. Worth, New York

46. Maret S, Franken P, Dauvilliers Y, Ghyselinck NB, Chambon P, Tafti M (2005) Retinoic acid signaling affects cortical synchrony during sleep. Science 310(5745):111-113. doi:10.1126/sci ence. 1117623

47. Marston OJ, Williams RH, Canal MM, Samuels RE, Upton N, Piggins HD (2008) Circadian and dark-pulse activation of orexin/ hypocretin neurons. Mol Brain 1:19. doi:10.1186/1756-6606-1-19

48. Mathews II, Erion MD, Ealick SE (1998) Structure of human adenosine kinase at 1.5 A resolution. Biochemistry 37(45):1560715620. doi:10.1021/bi9815445.bi9815445

49. Montagnese S, Middleton B, Mani AR, Skene DJ, Morgan MY (2009) Sleep and circadian abnormalities in patients with cirrhosis: features of delayed sleep phase syndrome? Metab Brain Dis 24(3):427-439. doi:10.1007/s11011-009-9146-5

50. Nestler EJ, Carlezon WA Jr (2006) The mesolimbic dopamine reward circuit in depression. Biol Psychiatry 59(12):1151-1159. doi:10.1016/j.biopsych.2005.09.018

51. Oster H, Werner C, Magnone MC, Mayser H, Feil R, Seeliger MW, Hofmann F, Albrecht U (2003) cGMP-dependent protein kinase II modulates mPer1 and mPer2 gene induction and influences phase shifts of the circadian clock. Curr Biol 13 (9):725-733

52. Palchykova S, Winsky-Sommerer R, Shen HY, Boison D, Gerling A, Tobler I (2010) Manipulation of adenosine kinase affects sleep regulation in mice. J Neurosci 30(39):13157-13165. doi:10.1523/ JNEUROSCI.1359-10.2010

53. Perlmann T, Jansson L (1995) A novel pathway for vitamin A signaling mediated by RXR heterodimerization with NGFI-B and NURR1. Genes Dev 9(7):769-782

54. Porkka-Heiskanen T, Alanko L, Kalinchuk A, Stenberg D (2002) Adenosine and sleep. Sleep Med Rev 6(4):321-332

55. Preitner N, Damiola F, Lopez-Molina L, Zakany J, Duboule D, Albrecht U, Schibler U (2002) The orphan nuclear receptor REV-ERBalpha controls circadian transcription within the positive limb of the mammalian circadian oscillator. Cell 110 (2):251-260

56. Radulovacki M (1985) Role of adenosine in sleep in rats. Rev Clin Basic Pharm 5(3-4):327-339

57. Raizen DM, Zimmerman JE, Maycock MH, Ta UD, You YJ, Sundaram MV, Pack AI (2008) Lethargus is a Caenorhabditis 
elegans sleep-like state. Nature 451(7178):569-572. doi:10.1038/ nature 06535

58. Ripperger JA, Jud C, Albrecht U (2011) The daily rhythm of mice. FEBS Lett. doi:10.1016/j.febslet.2011.02.027

59. Ripperger JA, Schmutz I, Albrecht U (2010) PERsuading nuclear receptors to dance the circadian rhythm. Cell Cycle 9 (13):2513-2519

60. Sakurai T, Amemiya A, Ishii M, Matsuzaki I, Chemelli RM, Tanaka H, Williams SC, Richardson JA, Kozlowski GP, Wilson S, Arch JR, Buckingham RE, Haynes AC, Carr SA, Annan RS, McNulty DE, Liu WS, Terrett JA, Elshourbagy NA, Bergsma DJ, Yanagisawa M (1998) Orexins and orexin receptors: a family of hypothalamic neuropeptides and $G$ protein-coupled receptors that regulate feeding behavior. Cell 92(4):573-585

61. Salomon RM, Ripley B, Kennedy JS, Johnson B, Schmidt D, Zeitzer JM, Nishino S, Mignot E (2003) Diurnal variation of cerebrospinal fluid hypocretin-1 (Orexin-A) levels in control and depressed subjects. Biol Psychiatry 54(2):96-104

62. Saper CB, Fuller PM, Pedersen NP, Lu J, Scammell TE (2010) Sleep state switching. Neuron 68(6):1023-1042. doi:10.1016/j. neuron.2010.11.032

63. Schmutz I, Ripperger JA, Baeriswyl-Aebischer S, Albrecht U (2010) The mammalian clock component PERIOD2 coordinates circadian output by interaction with nuclear receptors. Genes Dev 24(4):345-357. doi:10.1101/gad.564110

64. Schwiebert EM, Zsembery A (2003) Extracellular ATP as a signaling molecule for epithelial cells. Biochim Biophys Acta 1615(1-2):7-32

65. Sei H (2008) Vitamin A and sleep regulation. J Med Invest 55 $(1-2): 1-8$

66. Shostak A, Landgraf D, Oster H (2011) Clock genes and sleep. Pflugers Arch-Eur J Physiol (in press)

67. Steenland HW, Wu V, Fukushima H, Kida S, Zhuo M (2010) CaMKIV over-expression boosts cortical 4-7 Hz oscillations during learning and $1-4 \mathrm{~Hz}$ delta oscillations during sleep. Mol Brain 3:16. doi:10.1186/1756-6606-3-16

68. Steindl PE, Ferenci P, Marktl W (1997) Impaired hepatic catabolism of melatonin in cirrhosis. Ann Intern Med 127(6):494

69. Steindl PE, Finn B, Bendok B, Rothke S, Zee PC, Blei AT (1995) Disruption of the diurnal rhythm of plasma melatonin in cirrhosis. Ann Intern Med 123(4):274-277

70. Strecker RE, Morairty S, Thakkar MM, Porkka-Heiskanen T, Basheer R, Dauphin LJ, Rainnie DG, Portas CM, Greene RW, McCarley RW (2000) Adenosinergic modulation of basal forebrain and preoptic/anterior hypothalamic neuronal activity in the control of behavioral state. Behav Brain Res 115 (2): 183-204

71. Sullivan SS, Guilleminault C (2009) Emerging drugs for insomnia: new frontiers for old and novel targets. Expert Opin Emerg Drugs 14(3):411-422. doi:10.1517/14728210903171948
72. Taheri S, Sunter D, Dakin C, Moyes S, Seal L, Gardiner J, Rossi M, Ghatei M, Bloom S (2000) Diurnal variation in orexin A immunoreactivity and prepro-orexin mRNA in the rat central nervous system. Neurosci Lett 279(2):109-112

73. Tanaka S, Kodama T, Nonaka T, Toyoda H, Arai M, Fukazawa M, Honda Y, Honda M, Mignot E (2010) Transcriptional regulation of the hypocretin/orexin gene by NR6A1. Biochem Biophys Res Commun 403(2):178-183. doi:10.1016/j.bbrc.2010.11.001

74. Um JH, Pendergast JS, Springer DA, Foretz M, Viollet B, Brown A, Kim MK, Yamazaki S, Chung JH (2011) AMPK regulates circadian rhythms in a tissue- and isoform-specific manner. PLoS One 6(3):e18450. doi:10.1371/journal.pone.0018450

75. Um JH, Yang S, Yamazaki S, Kang H, Viollet B, Foretz M, Chung $\mathrm{JH}$ (2007) Activation of 5'-AMP-activated kinase with diabetes drug metformin induces casein kinase Iepsilon (CKIepsilon)dependent degradation of clock protein mPer2. J Biol Chem 282 (29):20794-20798. doi:10.1074/jbc.C700070200

76. Vanselow K, Kramer A (2007) Role of phosphorylation in the mammalian circadian clock. Cold Spring Harb Symp Quant Biol 72:167-176. doi:10.1101/sqb.2007.72.036

77. Vyazovskiy VV, Olcese U, Hanlon EC, Nir Y, Cirelli C, Tononi G (2011) Local sleep in awake rats. Nature 472(7344):443-447. doi:10.1038/nature10009

78. Wei F, Qiu CS, Liauw J, Robinson DA, Ho N, Chatila T, Zhuo M (2002) Calcium calmodulin-dependent protein kinase IV is required for fear memory. Nat Neurosci 5(6):573-579. doi:10.1038/nn855

79. Wisor JP, O'Hara BF, Terao A, Selby CP, Kilduff TS, Sancar A, Edgar DM, Franken P (2002) A role for cryptochromes in sleep regulation. BMC Neurosci 3:20

80. Xu Y, Padiath QS, Shapiro RE, Jones CR, Wu SC, Saigoh N, Saigoh K, Ptacek LJ, Fu YH (2005) Functional consequences of a CKIdelta mutation causing familial advanced sleep phase syndrome. Nature 434(7033):640-644. doi:10.1038/nature03453

81. Yin L, Wang J, Klein PS, Lazar MA (2006) Nuclear receptor Reverbalpha is a critical lithium-sensitive component of the circadian clock. Science 311(5763):1002-1005. doi:10.1126/science.1121613

82. Yin L, Wu N, Curtin JC, Qatanani M, Szwergold NR, Reid RA, Waitt GM, Parks DJ, Pearce KH, Wisely GB, Lazar MA (2007) Rev-erbalpha, a heme sensor that coordinates metabolic and circadian pathways. Science 318(5857):1786-1789. doi:10.1126/ science. 1150179

83. Zhang J, Kaasik K, Blackburn MR, Lee CC (2006) Constant darkness is a circadian metabolic signal in mammals. Nature 439 (7074):340-343. doi:10.1038/nature04368

84. Zhang X, Beaulieu JM, Sotnikova TD, Gainetdinov RR, Caron MG (2004) Tryptophan hydroxylase-2 controls brain serotonin synthesis. Science 305(5681):217. doi:10.1126/science.1097540.305/5681/217

85. Zimmermann H (2000) Extracellular metabolism of ATP and other nucleotides. Naunyn Schmiedebergs Arch Pharmacol 362 (4-5):299-309 